\title{
Income Segregation and the Incomplete Integration of Islam in the Paris Metropolitan Area
}

Socius: Sociological Research for a Dynamic World Volume 6: I-3

(C) The Author(s) 2020 Article reuse guidelines: sagepub.com/journals-permissions DOI: 10.1 | $77 / 2378023$ | I9899585 srd.sagepub.com

(S)SAGE

\section{Lucas G. Drouhot'}

\begin{abstract}
In France as in many other Western European countries, the purported concentration of large Muslim populations in disadvantaged areas at the outskirts of major cities has been associated with public and scholarly concerns for failed integration, but few spatial data exist for the purposes of empirical study. Relying on a unique geolocated data set built from online repositories of Muslim places comprising halal butcher shops, prayer spaces, religious schools, and bookstores, the author uses a geographic information system to map Islamic institutions in the Paris metropolitan area. Contrary to the religious segregation narrative, the presence of Islamic institutions is widespread within the city. Using census income data aggregated by neighborhoods, however, the author shows that the spatial distribution of Muslim institutions matches broader dynamics of income segregation within the entire metropolitan area. Despite urban mainstreaming suggested by a substantial presence within the city proper, the spatial integration of Islam thus remains incomplete.
\end{abstract}

\section{Keywords}

urban sociology, GIS, segregation, immigration, Islam

In many Western European countries, the purported concentration of large Muslim populations in disadvantaged urban areas has been associated with public and scholarly concerns for failed integration (Drouhot and Nee 2019). In France, political discourse linking Muslims to "parallel societies" and religious ghettos has crystallized anxiety around the so-called banlieues. In its commonsensical use, the term designates impoverished urban areas that have historically been home to immigrant families from Muslim-majority countries that settled in France in the postwar era, and that are generally located at the outskirts of major cities and away from their wealthier urban core. In the aftermath of the January 2015 terror attacks at the Charlie Hebdo headquarters, then prime minister Manuel Valls pointed to a "spatial, social, ethnic apartheid" as a root cause of the attacks, adding that although such violence could not be excused, it was necessary to look "at our country's reality" (de la Baume 2015).

Despite such policy narratives, as well as canonical ethnographic descriptions of Muslim communities living in the banlieues (e.g., Kepel 1987), the extent of Islam's isolation from the more affluent and mainstream urban centers has hitherto remained unknown. Such a knowledge gap reflects well-known taboos regarding data collection on ethnic and religious groups stemming from French Republicanism (Simon 2008).
Relying on a unique geolocated data set built from online repositories of Muslim institutions comprising halal butcher shops, prayer spaces, religious schools, and bookstores (Drouhot 2019), I use road network analysis-a geographic information system technique to realistically measure distances according to the constraints imposed by the built environment, unlike "as-the-crow-flies" distance (Curtin 2007) - to map the catchment areas of Islamic institutions in the Paris metropolitan area (Figure 1A). I complement this data source with household income data from the French census aggregated by iris, small census spatial units matching neighborhoods in size (Figure 1B).

Figure 1A shows patterns of spatial clustering where multiple types of Muslim institutions overlap, forming institutionally integrated areas where religious followers can find different services in compact urban spaces. The presence of Muslim institutions inside Paris and in areas holding high symbolic value in the French imaginary is widespread; for

'Max Planck Institute for the Study of Religious and Ethnic Diversity, Göttingen, Germany

\section{Corresponding Author:}

Lucas G. Drouhot, Max Planck Institute for the Study of Religious and Ethnic Diversity, II Hermann-Föge Weg, 37073 Göttingen, Germany E-mail: drouhot@mmg.mpg.de 

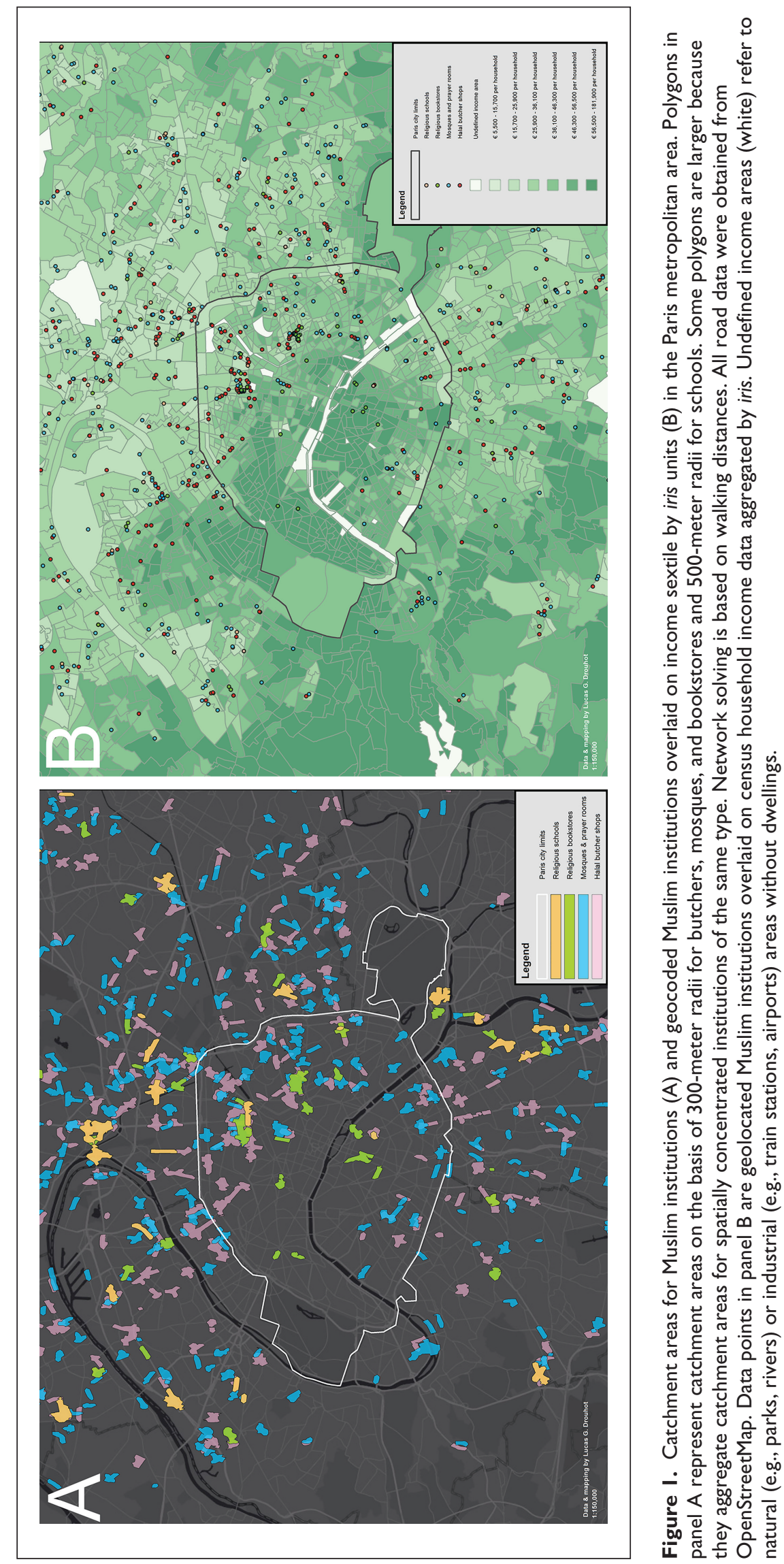
instance, the large cluster in northern Paris in the so-called Goutte d'Or neighborhood is immediately east of the popular and touristy Montmartre neighborhood. This pattern of spatial inclusion belies the popular notion that Islam is rooted primarily in the banlieues. Figure 1B, however, suggests that the spatial distribution of Islamic institutions follows broader dynamics of income segregation within the entire metropolitan area, with a strong presence in the markedly poorer areas of the southeast, east, and north and little presence in the wealthier areas of western Paris and suburbs where the economic elites reside.

Despite spatial mainstreaming suggested by a substantial presence within Paris proper, income segregation constitutes a more salient feature in the data than the Paris/banlieue distinction. Given the salience of such a key aspect of social inequality, the aggregate spatial pattern characterizing Muslim institutions in the Paris metropolitan area at large is one of incomplete integration.

\section{Acknowledgments}

I thank Mauricio Bucca, Camaron Cohen, Lorène Guerre, C. J. Randall, and Miriam Schader for comments on earlier version of this article.

\section{ORCID iD}

Lucas G. Drouhot iD https://orcid.org/0000-0001-8080-6212

\section{Supplemental Material}

Supplemental material for this article is available online.

\section{References}

Curtin, Kevin M. 2007. "Network Analysis in Geographic Information Science: Review, Assessment, and Projections." Cartography and Geographic Information Science 34(2):103-11.

de la Baume, Maïa. 2015. "French Premier Says 'Apartheid' Is Leaving Minorities on the Fringe." The New York Times. Retrieved December 24, 2019. https://www.nytimes.com/2015/ 01/21/world/europe/paris-attacks-suspects.html.

Drouhot, Lucas G. 2019. "MAPISLAM: A Spatial Dataset of Muslim Institutions in Urban France." Version 1.0. Cologne, Germany: GESIS Datenarchiv.

Drouhot, Lucas G., and Victor Nee. 2019. "Assimilation and the Second Generation in Europe and America: Blending and Segregating Social Dynamics between Immigrants and Natives" Annual Review of Sociology 45:177-99.

Kepel, Gilles. 1987. Les Banlieues de l'Islam. Naissance d'une Religion en France. Paris: Seuil.

Simon, Patrick. 2008. "The Choice of Ignorance: The Debate of Ethnic and Racial Statistics in France." French Politics, Culture \& Society 26(1):7-31.

\section{Author Biography}

Lucas G. Drouhot is a postdoctoral research fellow at the Max Planck Institute for the Study of Religious and Ethnic Diversity (Göttingen, Germany), with substantive interests in international migration, social networks, and social stratification. His current research agenda focuses on the incorporation of the children of immigrants in Western Europe and the United States, with an empirical focus on social mobility trajectories, friendship patterns, and acculturation dynamics as they relate to broader processes of assimilation. He holds a PhD in sociology from Cornell University. 